\title{
ACIDENTES DE TRÂNSITO E A FREQUÊNCIA DOS EXAMES DE ALCOOLEMIA COM VÍTIMAS FATAIS NA CIDADE DO RIO DE JANEIRO
}

\author{
Traffic accidents with fatal victims and alcohol consumption \\ in Rio de Janeiro City \\ Accidentes de tránsito y la frecuencia de los exámenes de
alcoholemia con víctimas fatales en la ciudad del Rio de Janeiro.
}

\section{RESUMO}

Estudo epidemiológico descritivo. 0 objetivo foi analisar os óbitos por acidentes de trânsito, registrados no Instituto Médico Legal (IML), na cidade do Rio de Janeiro, segundo a frequência de realização dos exames sobre os níveis de alcoolemia. Foram analisados 533 prontuários, no período de seis meses, que corresponderam a 12,3\% do total de mortes registradas. Evidenciouse que o exame de alcoolemia foi prioritariamente realizado nas vítimas que vieram de via pública e deram entrada no IML nas primeiras 12 horas após o acidente. A realização dos testes de alcoolemia teve significativa relação com o tempo decorrido entre 0 acidente e o óbito. Identificou-se, contudo, grande perda de oportunidade de realização do exame para um grande número de vítimas vindas diretamente de via pública nas primeiras 12 horas do acidente $(50,1 \%)$, colaborando para uma subnotificação dos verdadeiros números de álcool no trânsito.

Palavras-chave: Mortalidade. Acidentes de Trânsito. Bebidas Alcoólicas.

\begin{abstract}
Abstract: The objective was to analyze deaths by traffic accidents registered at the Medical Legal Institute (IML) of the Rio de Janeiro city, based on frequency of the level of alcoholemy exams performed. We analyzed 533 records for a six-month period that corresponds to $12.3 \%$ of the total number of deaths registered at the IML. It was identified that the alcoholemy exams were prioritized, being done primarily with victims coming from public streets, and got to the IML in the twelve first hours after the accident. The performance of the alcoholemy exams had a significant relationship with the time between the accident and the death occurrence. The study showed that a big opportunity is lost to perform exams in a great number of victims that come straight from public streets during the twelve first hours after the accident $(50,1 \%)$, collaborating for a sub notification of the true numbers of alcohol in transit
\end{abstract}

Keywords: Mortality. Traffic accidents. Alcoholic beverages.

\section{Resumen}

El objetivo fue analizar las muertes por accidentes de tránsito, registrados en el Instituto Médico Legal (IML), en la ciudad del Rio de Janeiro, según la frecuencia de realización de los exámenes sobre los niveles de alcoholemia. Fueran analizados 533 prontuarios, en el periodo de seis meses, que correspondieron a $12,3 \%$ del total de muertes registradas. Hay evidencias que el examen de alcoholemia fue prioritariamente realizado en las víctimas que vinieran de la calle y dieron entrada en el IML en las primeras 12 horas después del accidente. La realización de los testes de alcoholemia tuvo significativa relación con el tiempo transcurrido entre el accidente y la muerte. Se han identificado, sin embargo, gran pérdida de oportunidad de realización del examen para un gran número de víctimas venidas directamente de la calle en las primeras 12 horas del accidente $(50,1 \%)$, colaborando para una subnotificación de los verdaderos números de alcohol en el tránsito.

Palabras clave: Mortalidad. Accidentes de tránsito. Bebidas alcohólicas.

\footnotetext{
Professora Adjunta do Departamento de Saúde Publica da Escola de Enfermagem Anna Nery/Universidade Federal do Rio de Janeiro - RJ e Coordenadora do NAIAT/HESFA/UFRJ. Brasil. E-mail: angelabreu@globo.com, ²Professor Associado I da Faculdade de Medicina - Instituto de neurologia Deolindo Couto-UFRJ e Coordenador do Cepral/UFRJ. Brasil. E-mail: jmbl@evolucaovida.com.br, 3Pesquisadora do Laboratório de Educação Saúde e Ambiente do Departamento de Biologia do Instituto Osvaldo Cruz - IOC/ FIO - CRUZ. Brasil. E-mail: rohgriep@terra.com.br
} 


\section{INTRODUCÃO}

Segundo relatório da Organização Mundial de Saúde-OMS, a cada dia morrem no mundo, em acidentes de trânsito, mais de 3.000 pessoas, ou seja, em um ano morrem 1,2 milhão de pessoas, e estima-se uma morte a cada trinta segundos. 0 número de vítimas fatais aumentou consideravelmente nos países em desenvolvimento ${ }^{1}$. Dessa forma, observa-se que os acidentes de trânsito constituem hoje uma verdadeira e urgente questão de saúde pública no mundo moderno.

A OMS ainda destaca que, para a redução desses óbitos, há a necessidade de melhorar as vias de circulação e a gestão do tráfego e aumentar as medidas de segurança dos veículos, além da maior atenção no combate do dirigir sob efeito do álcool. Sobretudo, nos países em desenvolvimento, onde existe forte cultura do uso de bebidas alcoólicas por jovens, a atenção das autoridades deve ser redobrada ${ }^{1}$.

No Brasil, o número de mortes nos acidentes de trânsito voltou a subir; parece que o impacto da implantação do novo Código Brasileiro de Trânsito está passando, conforme pode ser observado nos dados estatísticos do Ministério da Saúde, quando os registros foram de 32.753 óbitos em 2002, enquanto

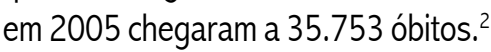

Apesar da entrada em vigor do novo Código Brasileiro de Trânsito em 1998, podemos observar que o número de acidentes ainda se encontra elevado, quando comparado a outros países. 0 álcool tem sido apontado como um dos principais fatores de risco nessas estatísticas, estimando-se que $70 \%$ dos casos fatais dos acidentes de trânsito estão relacionados com o uso e 0 abuso dessas bebidas ${ }^{3}$.

Nesse sentido, muitos pesquisadores nacionais vêm, ao longo do tempo, apresentando estudos associados ao uso do álcool e à direção, os quais sublinham a relevância da relação álcool e trânsito e reafirmam que o uso e o abuso de bebidas alcoólicas ocupam posto proeminente entre as causas de acidentes automobilísticos ${ }^{3-6}$.

Estudo realizado sobre a incidência dos acidentes nas emergências de três hospitais do Rio de Janeiro, no período de um ano, de 2000 a 2001, totalizou 19.481 atendimentos provocados por acidentes do trânsito. No entanto, nenhum deles relatou a ocorrência dos exames de alcoolemia realizados, com essas vítimas do trânsito, nas emergências desses hospitais ${ }^{4,7}$. Mesmo aquelas vítimas fatais que vão para o IML, uma parte considerável delas fica sem realizar o exame de alcoolemia, apesar de dar entrada nas primeiras 12 horas decorridas da morte 8 .

Embora seja conhecido que o consumo do álcool aumenta a probabilidade de choques que causam a morte ou traumatismos graves, ainda é difícil estabelecer comparações entre diversos estudos, devido às grandes variações que existem de um país para outro nos limites legais de alcoolemia impostos pela legislação local.'
No Brasil, por exemplo, o novo código Nacional de Trânsito estabelece, em seu Artigo 276, o nível de alcoolemia limite de $0,6 \mathrm{~g} / \mathrm{l}$ ou equivalente para outras formas de medida (bafômetro, etc). Na América Latina, podemos citar alguns países como exemplos de variações dentro dos níveis de alcoolemia: Argentina, 0,5g//; El Salvador, 1,0 g/l; México, 0,8g/l e outros onde nem sequer existem normas a respeito, como: Cuba, Bolívia, Haiti, Paraguai, etc. Muitos países europeus e vários estados dos Estados Unidos fixaram limites de alcoolemia de $0,2 \mathrm{~g} / \mathrm{l}$ para motoristas jovens, geralmente menores de 21 $\operatorname{anos}^{1,4,9}$

Nesse contexto, estudos que permitam conhecer o impacto do uso e abuso do álcool na morbimortalidade relacionada aos acidentes e suas repercussões na cidade do Rio de Janeiro se fazem necessários, subsidiando elaborações de políticas públicas de prevenção. Dessa forma, esse estudo tem como objetivo analisar os óbitos por acidentes de trânsito registrados no Instituto Medico Legal (IML), segundo a frequência de realização dos exames sobre níveis de alcoolemia.

\section{METODOLOGIA DO ESTUDO}

0 estudo foi realizado no Instituto Médico Legal Afrânio Peixoto (IML-AP), do Rio de Janeiro, para onde são encaminhadas todas as vítimas fatais envolvidas em causas violentas do município e áreas adjacentes.

Verificaram-se todos os prontuários de vítimas fatais por acidentes de trânsito (colisão, atropelamento, choque, queda de motos, outros) ocorridos na cidade do Rio de Janeiro, retiradas do universo das vítimas por todas as causas externas, registradas no IML em dois períodos, num total de seis meses (dezembro de 2001, janeiro e fevereiro de 2002, dezembro de 2003, e janeiro e fevereiro de 2004). Assim, identificaramse, dentre os 4.316 óbitos por causas externas, 533 (12,3\%) óbitos por acidentes de trânsito no Município do Rio de Janeiro. Optou-se por utilizar o termo "acidentes de trânsito" para todas as ocorrências, englobando também os acidentes de transporte. Esses acidentes estão classificados no capítulo XX da Classificação Internacional de Doença - CID 10, figurando entre os códigos V01 a Y9.

Estudaram-se variáveis relacionadas às características sociodemográficas (sexo e faixa etária); às características dos acidentes (turno, dia da semana, local do óbito, tipo de acidente, tempo do óbito) e alcoolemia.

A variável turno foi categorizada a partir do horário do acidente referido nos prontuários: das 6 às 12 horas = manhã; das 13 às 18 horas $=$ tarde; das 19 às 24 horas $=$ noite; $e$ da primeira hora às 5 horas $=$ madrugada.

No primeiro período do estudo, de dezembro de 2001 a janeiro e fevereiro de 2002, a técnica utilizada no IML para detectar a alcoolemia era de oxirredução, cujo limite de detecção era de $0,6 \mathrm{~g} / \mathrm{l}$. Portanto, estabeleceu-se como ponto de corte para determinar a alcoolemia o nível alcoólico $\geq 0,6 \mathrm{~g} / \mathrm{l}$ de sangue no organismo. 
No segundo período do estudo, de dezembro de 2003 a fevereiro de 2004, o IML passou a utilizar a técnica de cromatografia gasosa. Nessa técnica, era possível detectar níveis de álcool que o laboratório fixava para separar as amostras positivas, ou seja, $\geq 0,1 \mathrm{~g} / \mathrm{l}$ de etanol no sangue. Optou-se, assim, por identificar níveis de alcoolemia $<0,6 \mathrm{~g} / \mathrm{l}$.

Adotou-se, para identificação do local da ocorrência, a divisão administrativa por Áreas de Planejamento (AP), utilizada pelo setor de saúde para o município do Rio de Janeiro. Além disso, os óbitos ainda foram agrupados em: Baixada Fluminense (Belford Roxo, Duque de Caxias, Guapimirim, Itaguaí, Japeri, Magé, Mangaratiba, Mesquita, Nilópolis, Nova Iguaçu, Paracambi, Queimados, S. J. Meriti, Vila Kennedy, Vilar dos Teles) e outros (Itaboraí, Niterói, São Gonçalo, Ponte Rio Niterói, Cachoeiro de Macacu, Volta Redonda, Silva Jardim,
Saquarema, Teresópolis, Piabetá, Rio Bonito, Rodovia Rio Santos).

Após a coleta, os dados do estudo foram processados eletronicamente através do Programa EPI-Info (versão 2003) e analisados estatisticamente através do programa SPSS (versão 12).

As análises bivariadas foram feitas a partir de estatísticas descritivas e apresentadas em tabelas. Médias foram comparadas através do teste $t$ de Student e ANOVA. 0 teste do qui-quadrado de Pearson foi utilizado para avaliação de associação entre variáveis categóricas, sendo adotado o nível de 5\% para significância estatística.

0 estudo foi submetido aos procedimentos normativos do Comitê de Ética do Instituto Médico Legal Afrânio Peixoto/RJ, protocolo $n^{0}$. 121/1540/GAB/05.

\section{RESULTADOS}

Tabela 1 - Distribuição dos óbitos por acidentes de trânsito, segundo a realização do teste e índice de alcoolemia. Município do Rio de Janeiro.

Dez/2001, Jan-Fev/2002 e Dez/2003, Jan-Fev/2004

\begin{tabular}{|c|c|c|c|c|c|c|}
\hline \multicolumn{7}{|c|}{ Testes de Alcoolemia } \\
\hline \multirow{3}{*}{ Períodos } & \multirow{2}{*}{\multicolumn{2}{|c|}{ Total }} & \multicolumn{3}{|c|}{ Alcoolemia } & \\
\hline & & & \multicolumn{2}{|c|}{ Realizado } & \multicolumn{2}{|c|}{ Não realizado } \\
\hline & $n$ & $\%$ & $\mathrm{n}$ & $\%$ & $n$ & $\%$ \\
\hline Período 2001-2002 & 266 & 100,0 & 88 & 33,1 & 178 & 66,9 \\
\hline Período 2003-2004 & 267 & 100,0 & 93 & 34,8 & 174 & 65,2 \\
\hline Total & 533 & 100,0 & 181 & 34,8 & 352 & 66,0 \\
\hline
\end{tabular}

Índices de Alcoolemia

\begin{tabular}{|c|c|c|c|c|c|c|}
\hline \multirow{3}{*}{ Períodos } & \multirow{2}{*}{\multicolumn{2}{|c|}{ Total }} & \multicolumn{4}{|c|}{ Alcoolemia } \\
\hline & & & \multicolumn{2}{|c|}{ Detectado $\left(^{*}\right)$} & \multicolumn{2}{|c|}{ Não detectado } \\
\hline & $\mathrm{n}$ & $\%$ & $\mathrm{n}$ & $\%$ & $\mathrm{n}$ & $\%$ \\
\hline Período 2001-2002 & 88 & 100,0 & 32 & 36,4 & 56 & 63,6 \\
\hline Período 2003-2004 & 93 & 100,0 & 45 & 48,4 & 48 & 51,6 \\
\hline Total & 181 & 100,0 & 77 & 42,5 & 104 & 57,5 \\
\hline
\end{tabular}

(*) 2001-2002 - utilizando a técnica de oxirredução ( $\geq 0,6 \mathrm{~g} / \mathrm{l})$.

2003-2004 - utilizando a técnica de cromatografia gasosa $(\geq 0,1 \mathrm{~g} / \mathrm{l})$.

Na Tabela 1, observa-se que, do total de óbitos ocorridos nos períodos avaliados, apenas para 181 vítimas (34,8\%) foi realizado o exame de alcoolemia. Desses, 42,5\% apresentaram índices de alcoolemia detectada. Duas técnicas diferenciadas foram utilizadas: a técnica de oxirredução no período 2001-2002, e a técnica de cromatografia gasosa no período 2003-2004, contudo as freqüências de detecção foram semelhantes nos dois períodos. 
Tabela 2 - Distribuição dos óbitos por acidentes de trânsito, segundo os níveis de alcoolemia detectados. Município do Rio de Janeiro. Dez/2001, Jan-Fev/2002 e Dez/2003, Jan-Fev/2004

\begin{tabular}{|c|c|c|c|c|c|c|}
\hline \multirow{3}{*}{$\begin{array}{l}\text { Níveis de alcoolemia } \\
\text { detectados em } \mathrm{g} / \mathrm{l}\end{array}$} & \multirow{2}{*}{\multicolumn{2}{|c|}{ Total }} & \multicolumn{4}{|c|}{ Período ${ }^{(*)}$} \\
\hline & & & \multicolumn{2}{|c|}{ 2001-2002 } & \multicolumn{2}{|c|}{ 2003-2004 } \\
\hline & $n$ & $\%$ & $\mathrm{n}$ & $\%$ & $n$ & $\%$ \\
\hline 0,1 a 0,39 & 17 & 22,3 & $0^{(*)}$ & 0,0 & 17 & 37,7 \\
\hline 0,40 a 0,59 & 1 & 1,2 & $0^{(*)}$ & 0,0 & 1 & 2,3 \\
\hline 0,60 a 2,0 & 51 & 66,2 & 29 & 90,6 & 22 & 48,8 \\
\hline Acima de 2,0 & 8 & 10,3 & 3 & 9.4 & 5 & 11.2 \\
\hline Total & 77 & 100,0 & 32 & 100,0 & 45 & 100,0 \\
\hline
\end{tabular}

(") 2001-2002 - técnica da oxirredução. 2003-2004 - técnica da cromatografia gasosa.

(*) Valores abaixo de $0,6 \mathrm{~g} / \mathrm{I}$ não são avaliados pela técnica de oxirredução.

Observa-se na Tabela 2 que, dos exames de alcoolemia detectados, $22,3 \%$ apresentaram resultados entre os valores de 0,1 e 0,39 g/l de sangue no organismo, e 66,2\% apresentaram alcoolemia de 0,6 a 2,0 $\mathrm{g} / \mathrm{l}$ de sangue, e 10,3\%, acima de 2,0 $\mathrm{g} / \mathrm{lde}$ sangue.

Tabela 3 - Distribuição do perfil das vítimas e das características dos acidentes de trânsito, segundo realização do exame de alcoolemia. Município do Rio de Janeiro.

Dez/2001, Jan-Fev/2002 e Dez/2003, Jan-Fev/2004

\begin{tabular}{|c|c|c|c|c|c|c|c|}
\hline \multirow{3}{*}{ Variáveis ${ }^{(* *)}$} & \multirow{2}{*}{\multicolumn{2}{|c|}{ Total }} & \multicolumn{4}{|c|}{ Alcoolemia } & \multirow{3}{*}{ Valor $\mathrm{p}$} \\
\hline & & & \multicolumn{2}{|c|}{ Não Realizado } & \multicolumn{2}{|c|}{ Realizado } & \\
\hline & $\mathrm{n}$ & $\%$ & $N$ & $\%$ & $\mathrm{n}$ & $\%$ & \\
\hline \multicolumn{8}{|l|}{ Sexo } \\
\hline Masculino & 430 & 100,0 & 284 & 66,0 & 146 & 34,0 & \multirow{3}{*}{0,996} \\
\hline Feminino & 103 & 100,0 & 68 & 66,0 & 35 & 34,0 & \\
\hline Total & 533 & 100,0 & 352 & 66,0 & 181 & 34,0 & \\
\hline \multicolumn{8}{|l|}{ Faixa etária } \\
\hline De 1 a 13 anos & 27 & 100,0 & 27 & $100, C$ & $\mathrm{O}$ & 0,0 & \multirow{6}{*}{$p$ á 0,0001} \\
\hline De 14 a 25 anos & 112 & 100,0 & 75 & 67,0 & 37 & 33,0 & \\
\hline De 26 a 39 anos & 115 & 100,0 & 63 & 54,0 & 52 & 45,2 & \\
\hline De 40 a 59 anos & 160 & 100,0 & 98 & 61,3 & 62 & 38,8 & \\
\hline De 60 anos e mais & 111 & 100,0 & 83 & 74,8 & 28 & 25,2 & \\
\hline Total & 525 & 100,0 & 346 & 65,9 & 179 & 34,1 & \\
\hline \multicolumn{8}{|l|}{ Tipo de acidente } \\
\hline Atropelamento & 323 & 100,0 & 235 & 72,8 & 88 & 27,2 & \multirow{7}{*}{$p$ á 0,000 1} \\
\hline Colisão & 109 & 100,0 & 55 & 50,5 & 54 & 49,5 & \\
\hline Choque & 12 & 100,0 & 8 & 66,7 & 4 & 33,3 & \\
\hline Queda de moto & 39 & 100,0 & 27 & 69,2 & 12 & 30,8 & \\
\hline Queda de bicicleta & 27 & 100,0 & 14 & 51,9 & 13 & 48,1 & \\
\hline Outros & 5 & 100,0 & 1 & 20,0 & 4 & 80,0 & \\
\hline Total & 515 & 100,0 & 340 & 66,0 & 175 & 34,0 & \\
\hline \multicolumn{8}{|l|}{ Local do Óbito } \\
\hline Via pública & 176 & 100,0 & 53 & 30,1 & 123 & 69,9 & \multirow{3}{*}{$p$ á 0,000 1} \\
\hline Hospital & 357 & 100,0 & 299 & 83,8 & 58 & 16,2 & \\
\hline Total & 533 & 100,0 & 352 & 66,0 & 182 & 34,0 & \\
\hline \multicolumn{8}{|l|}{ Dias da Semana } \\
\hline Segunda-feira & 69 & 100,0 & 45 & 65,2 & 24 & 34,8 & \multirow{8}{*}{$p$ á 0,000 1} \\
\hline Terça-feira & 65 & 100,0 & 55 & 84,6 & 10 & 15,4 & \\
\hline Quarta-feira & 68 & 100,0 & 52 & 76,5 & 16 & 23,5 & \\
\hline Quinta-feira & 52 & 100,0 & 41 & 78,8 & 11 & 21,2 & \\
\hline Sexta-feira & 76 & 100,0 & 48 & 63,2 & 28 & 36,8 & \\
\hline Sábado & 117 & 100,0 & 66 & 56,4 & 51 & 43,6 & \\
\hline Domingo & 80 & 100,0 & 40 & 50,0 & 40 & 50,0 & \\
\hline Total & 527 & 100,0 & 347 & 66,8 & 180 & 33,2 & \\
\hline \multicolumn{8}{|l|}{ Turno (*) } \\
\hline Manhã & 95 & 100,0 & 66 & 69,5 & 29 & 30,5 & \multirow{6}{*}{0,062} \\
\hline Tarde & 113 & 100,0 & 79 & 69,9 & 34 & 30,1 & \\
\hline Noite & 116 & 100,0 & 80 & 69,0 & 36 & 31,0 & \\
\hline Madrugada & 81 & 100,0 & 42 & 51,9 & 39 & 48,1 & \\
\hline Ignorado & 128 & 100,0 & 85 & 66,4 & 43 & 33,6 & \\
\hline Total & 533 & 100,0 & 352 & 66,0 & 181 & 34,0 & \\
\hline
\end{tabular}

$\left({ }^{*}\right)$ Não toram retirados os ignorados devido à alta trequência. $\left({ }^{* *}\right)$ Retirados os ignorados. 
Na Tabela 3, identificou-se a associação entre variáveis sociodemográficas e a realização do exame de alcoolemia. Em relação ao sexo, não houve diferenças nas frequências de realização do exame de alcoolemia. A realização do exame ocorreu a partir dos 14 anos de idade. A maior frequência de realização do teste foi identificada entre os óbitos de 26 a 39 anos (45,2\%); seguida da faixa etária de 40 a 59 anos (38,8\%); 14 a 25 anos (33\%); e 60 anos ou mais (25,2\%).

Quanto ao tipo de acidente, o estudo mostrou maior frequência de realização do exame de alcoolemia nos acidentes por colisão (49,5\%); seguidos das quedas de bicicleta $(48,1 \%)$ e dos de queda de moto $(30,8 \%)$.

Identificou-se, ainda, que 69,9\% dos exames de alcoolemia foram realizados em vítimas cujo acidente foi em via pública e apenas $16,2 \%$ dos exames foram realizados nas vítimas cujo óbito ocorreu no hospital. Em relação aos dias da semana, os dados mostraram tendência de aumento da frequência dos exames nos finais de semana. A avaliação da alcoolemia predominou entre os óbitos ocorridos no turno da madrugada, quando comparado aos outros turnos avaliados.

Tabela 4 - Distribuição dos óbitos por acidentes de trânsito, segundo o tempo do óbito e exame de alcoolemia realizado. Município do Rio de Janeiro.

Dez/2001, Jan-Fev/2002 e Dez/2003, Jan-Fev/2004

\begin{tabular}{|c|c|c|c|c|c|c|c|}
\hline \multirow{3}{*}{$\begin{array}{l}\text { Tempo do Óbito } \\
\text { (em horas) }\end{array}$} & \multirow{2}{*}{\multicolumn{2}{|c|}{ Total }} & \multicolumn{4}{|c|}{ Alcoolemia } & \multirow{3}{*}{ Valor $\mathrm{p}$} \\
\hline & & & \multicolumn{2}{|c|}{ Não Realizado } & \multicolumn{2}{|c|}{ Realizado } & \\
\hline & $\mathrm{n}$ & $\%$ & $\mathrm{n}$ & $\%$ & $\mathrm{~N}$ & $\%$ & \\
\hline$<12$ horas & 341 & 100,0 & 171 & 50,1 & 170 & 49,9 & \\
\hline 12 a 24 horas & 80 & 100,0 & 70 & 87,5 & 10 & 12,5 & 0,0001 \\
\hline Após 24 horas ou mais (") & 108 & 100,0 & 108 & 100,0 & 0 & 0,0 & \\
\hline Total & 529 & 100,0 & 349 & 66,0 & 180 & 36,6 & \\
\hline
\end{tabular}

(*) Média de permanência no hospital - 4,2 dias. Obs.: retirados os ignorados.

Observa-se, na Tabela 4, que o exame foi realizado em 49,9\% nas primeiras 12 horas do tempo decorrido do óbito e, em $12,5 \%$, entre 12 e 24 horas. Após as primeiras 24 horas de óbito, nenhum exame foi realizado. Observa-se que o exame deixou de ser realizado em $50,1 \%$ dos óbitos que chegaram ao IML nas primeiras 12 horas decorridas da morte.

\section{DISCUSSÃO DOS RESULTADOS}

0 estudo identificou uma baixa frequência de realização dos exames de alcoolemia, apenas $34,8 \%$ realizaram o exame. Esse resultado pode estar relacionado às dificuldades que a rotina do Serviço do IML enfrenta para realizar efetivamente esses testes em todas as vítimas de acidentes de trânsito que para lá são encaminhadas. Nesse sentido, o estudo mostrou que $50,1 \%$ dos óbitos que chegaram ao IML nas primeiras 12 horas, embora podendo realizar o exame, deixaram de fazê-lo. Esse quadro nos leva a pensar o quanto nossas estatísticas não evidenciam a verdadeira realidade dos fatos, colaborando para uma subnotificação dos verdadeiros números de acidentes relacionados ao álcool no trânsito.

Dos que realizaram o exame, $42,5 \%$ das vítimas fatais de acidentes de trânsito apresentavam alcoolemia positiva, das quais $66,2 \%$ com valores concentrados entre 0,6 e $2,0 \mathrm{~g} / \mathrm{l}$ de álcool no sangue, o que pode representar o uso excessivo de bebidas alcoólicas na ocasião; pelo menos mais de quatro a oito doses foram consumidas nas últimas horas antes do acidente. Isso nos mostra sério envolvimento do álcool com os acidentes de trânsito na cidade do Rio de Janeiro.
Embora a implantação do Código de Trânsito Brasileiro CTB tenha sido importante para a tomada de consciência dos problemas e ligeira queda inicial nos índices, o controle real dos infratores é limitado, uma vez que a caracterização do estado de embriaguez praticamente ficou restrita à perícia do Instituto Médico Legal, perdendo-se a chance de se identificar precocemente a presença do álcool no organismo. ${ }^{4}$

0 presente estudo registrou vítimas fatais com concentrações de álcool no sangue abaixo do limite legal de tolerância $(0,6 \mathrm{~g} / \mathrm{l})$ determinado pelo CTB, e também concentrações bem acima desse limite, bastante significativas no que tange ao trânsito. Como já se sabe, esses níveis de álcool no sangue levam desde a euforia e diminuição da vigilância até a incoordenação, fala comprometida e desorientação de tempo e espaçoç, ${ }^{3,4}$.

Todavia, nessa população, não se pôde identificar se foi 0 motorista ou o pedestre que estava alcoolizado abaixo ou acima do limite de tolerância e causou 0 acidente.

Nesse sentido, podemos considerar que o álcool estaria relacionado ao maior número de acidentes com vítimas fatais, 
se considerarmos que, em alguns casos, o causador do acidente, que está alcoolizado, é o motorista, que não morre e nem se fere, mas produz uma vítima fatal, e cujo estado de intoxicação não é identificado. Muitas vezes, a vítima por acidente de trânsito que vai parar no IML e tem como resultado de exame alcoolemia negativa, não foi o causador do acidente; quem o foi talvez tenha passado pelo hospital, apresentando alcoolemia considerável. Como já sabemos no atendimento da emergência não se faz alcoolemia de rotina para estes $\operatorname{casos}^{4}$, o que demonstra o quanto nossas estatísticas não evidenciam a verdadeira realidade dos fatos.

Observa-se, na Tabela 1 que, entre os $33,1 \%$ que realizaram o teste no período de 2001/2002, 36,4\% tinham valores maiores que $0,6 \mathrm{~g} / \mathrm{l}$. No entanto, $66 \%$ do total das vítimas não realizaram os exames nos dois períodos, fato que pode estar subestimando os reais valores de consumo do álcool entre usuários envolvidos em acidentes de trânsito, principalmente nas primeiras 24 horas do acidente. Sem dúvida, se considerarmos os valores estabelecidos de alcoolemia relacionados aos acidentes de trânsito de acordo com os níveis atualmente estabelecidos em alguns países da Europa, com limites que variam de 0 a $0,5 \mathrm{~g} / \mathrm{l}$ de sangue para os adultos condutores de veículos de quatro rodas, estaríamos contribuindo estatisticamente com números bem mais realistas de abuso de álcool no trânsito em nosso meio ${ }^{10}$.

Portanto, o presente estudo mostrou que $37,7 \%$ das vítimas fatais apresentaram índices de alcoolemia que, embora abaixo de 0,6 g/l - limite preconizado pelo Código de Trânsito Brasileiro de 1998 -, foram suficientes para levá-los a um trauma (colisão ou atropelamento) causado pelo trânsito e, consequentemente, à morte.

É importante destacar que, principalmente na ocorrência de acidentes de trânsito, o álcool está presente em grande parte com os níveis de alcoolemia detectados a partir de $0,1 \mathrm{~g} /$ I, conforme vêm demonstrando alguns estudos nacionais ${ }^{4,11-12}$. Esses dados vêm fortalecer a importância de se considerarem todos os valores de alcoolemia apresentados, principalmente quando temos um percentual bastante significativo (40\%), registrado no período estudado de 2003/2004, de alcoolemia abaixo de $0,6 \mathrm{~g} / \mathrm{l}$.

Estudos internacionais também vêm apontando concentração de alcoolemia entre 0,1 e 0,4 g/l envolvendo acidentes de trânsito ${ }^{1,13-14}$. 0 relatório americano ${ }^{14}$ ressalta que é considerado acidente de trânsito relacionado ao álcool se o motorista apresentar níveis de alcoolemia $\geq 0,1 \mathrm{~g} / \mathrm{l}$.

Ao relacionarmos o perfil das vítimas com as características dos acidentes de trânsito, segundo a realização do exame de alcoolemia, observou-se que, em relação à questão de gênero, não houve diferenças nas frequências de realização dos testes, embora os homens tenham apontado uma sobremortalidade em relação às mulheres, isto é, quatro vezes mais alta, o que podemos inferir à característica masculina quando se trata de violência urbana, quando o homem fica mais exposto. Observa- se a faixa etária de adultos jovens, como era de se esperar, apresentando maior frequência para a realização desse exame.

Contudo, chamou-nos atenção a faixa etária dos idosos, acima de 60 anos, apresentando uma frequência significativa para a realização dos exames de alcoolemia. Esse achado preocupa e alerta por ser um grupo que necessita de políticas públicas com maior direcionamento para esse fim, até porque o estudo mostra indivíduos atropelados que realizaram 0 exame de alcoolemia, o que leva a inferir que esta faixa etária poderá ter participação nesses resultados para a alcoolemia, inclusive por se tratar de país em desenvolvimento, onde infelizmente essa é uma característica ${ }^{1,9}$.

A Organização Mundial de Saúde ainda acrescenta que nos países de baixa e média renda, as pessoas com 60 anos e mais apresentavam as maiores taxas de mortalidade por 100.000 habitantes no ano de 2002; registraram-se 193.000 vítimas causadas pelo trânsito entre as pessoas nessa faixa etária. $\mathrm{E}$, ainda, que a taxa de mortalidade foi a mais elevada de todos os grupos de idade para esses países. ${ }^{1}$. Nos EUA, no ano de 2003, evidenciou-se que mais de um terço de todos os pedestres com 16 anos de idade ou idosos que morreram em acidentes de trânsito em 2003 tinham um nível de concentração de álcool no sangue de $0,8 \mathrm{~g} / \mathrm{l}$ ou mais, o que mostra a relação com o nosso trabalho no sentido da alcoolemia desses indivíduos. ${ }^{14}$

Ao examinarmos o local do óbito, percebemos que a maioria veio do hospital, no entanto, ao realizar exame de alcoolemia, 69,9\% eram provenientes de via pública. Esse resultado nos mostra que, na rotina do IML, são realizados exames de alcoolemia em maior quantidade às vítimas provenientes de via pública, o que era esperado, e em menor quantidade às oriundas do hospital. Nestas últimas, segundo informações do próprio IML e observação no local, eles estavam sendo realizados nas primeiras 24 horas pós-morte, ou melhor, naquelas vítimas que praticamente morreram ao chegar no hospital, o que pode ser explicado pelo fato de que, quanto maior a gravidade do acidente, maior é a chance de morrer no próprio local e maior a chance, de modo preponderante, de o álcool estar envolvido no acidente. Infelizmente, no Brasil, ainda não se realiza esse exame nas salas de trauma.

Por outro lado, estudo realizado nos EUA, em um hospital de trauma, mostrou que de 349 pacientes de 16 a 49 anos envolvidos em acidentes de trânsito, todos realizaram o exame de alcoolemia, e a concentração de álcool no sangue era o indicador principal do perigo do álcool no organismo. Os autores constataram que o maior risco estava entre os bebedores do tipo "farra", envolvendo $61 \%$ dos indivíduos atendidos. Eles ainda chamam a atenção para a importância desse exame, que deveria ser sistematicamente incluído na avaliação dos pacientes de trauma e usado como base para orientar os pacientes e intervenções de álcool em um centro de trauma. ${ }^{15}$

Neste sentido, em nosso país, estamos diante de um impasse: temos sérias restrições quanto à realização de exames 
de alcoolemia nos pacientes que chegam às emergências dos hospitais envolvidos em acidentes de trânsito, embora isso esteja previsto no atual Código de Trânsito Brasileiro. No entanto, há uma corrente que defende a ilegalidade de se realizar o exame de alcoolemia nos pacientes que vão para o hospital, ou mesmo da utilização do bafômetro, por se basear na Constituição Federal, dizendo que seu uso fere os direitos fundamentais do indivíduo: direito ao silêncio, ninguém é obrigado a produzir provas contra si mesmo. Dessa forma, a alcoolemia ficou restrita à perícia do IML, cujo controle real dos infratores é limitado. ${ }^{4}$

Observou-se no presente estudo a relação do uso e abuso do álcool desses acidentes com colisão, principalmente nos fins de semana, com uma tendência de aumento linear iniciando na sexta-feira até domingo, bem como pela madrugada e período da noite. Os períodos da madrugada, seguidos da noite, apresentaram maior tendência na realização dos exames pelo IML.

Dessa forma, observou-se que os dias e horários preferenciais para a ocorrência de acidentes de trânsito são os fins de semana entre noite e madrugada, relacionados com a alcoolemia, e, ainda, que o envolvimento do álcool em acidentes fatais na madrugada, principalmente com colisão, é maior do que durante 0 dia.

Podemos ainda acrescentar que, durante a noite e madrugada, geralmente os acidentes apresentam maior gravidade, em virtude de diversos fatores ligados ao meio ambiente (menor visibilidade) e aos usuários de via pública (excesso de velocidade, desrespeito aos sinais de trânsito, uso de álcool e drogas, violência, entre outros).

Vale ressaltar o tempo decorrido entre o acidente e o óbito, e os custos desses indivíduos para os cofres públicos, principalmente no hospital. 0 estudo demonstrou que esses indivíduos foram atendidos na emergência e tiveram em média 4,2 dias de permanência no hospital, vindo a falecer.

\section{CONSIDERAÇÕES FINAIS}

Os dados aqui apresentados reforçam o significativo envolvimento do álcool nos acidentes fatais de trânsito, embora mostrando que apenas $34,8 \%$ realizaram o exame de alcoolemia. Observou-se maior frequência da realização do teste para as colisões em fins de semana e principalmente para aqueles que vieram direto de via pública, no horário da madrugada, seguido da noite, sinalizando uma política de atuação nesse sentido.

Vale ressaltar o grande número de idosos com mais de 60 anos em que foi realizado o exame, nos apontando uma preocupação para essa faixa etária, um dado importante quando comparado ao percentual de atropelamento no presente estudo, caracterizando, dessa forma, um país em desenvolvimento, ainda com poucas ações e estratégias voltadas para a prevenção.

Em relação ao exame de alcoolemia, é preciso haver maior cobertura para a realização desses testes, conforme preconizado pelo Código de Trânsito Brasileiro, em vigor desde 1998.

É preciso que governo, sociedade e instituições de saúde façam um trabalho integrado para que se cumpram as leis do trânsito e que haja uma política mais eficaz, voltada para a questão da realização do exame de alcoolemia também nas emergências dos hospitais que atendem às vítimas dos acidentes de trânsito, bem como para otimizar esses exames no próprio IML, se possível com uma cober tura de $100 \%$ daqueles que dão entrada, com menos de 12 horas ocorridas da morte. Dessa forma, estaríamos contribuindo com níveis bem mais realistas de abuso de álcool no trânsito em nosso meio.

É primordial que estudos nesta área sejam fomentados no sentido de implementar ações de políticas públicas de saúde e educação permanente e a prevenção dos acidentes de trânsito.

\section{REFERÊNCIAS}

1-Organización Mundial de la Salud ( OMS). Informe mundial sobre prevención de los traumatismos causados por el transito. Resumen. Ginebra; 2004.

2 - Ministério da Saúde (MS) [on-line].Destaques do governo: mortes no transito aumentam 9\% em três anos; [acesso 9 maio 2007] Disponível em: http://portal.saude.gov.br/portal/aplicacoes/ noticias_detalhe.cfm?co_seq_noticia...

3- Lima JMB. Alcoologia: uma visão sistêmica dos problemas relacionados ao uso e abuso do álcool. Rio de Janeiro (RJ): UFRJ; 2003.

4- Abreu AMM. Mortalidade nos acidentes de transito na cidade do Rio de Janeiro relacionada ao uso e abuso de bebidas alcoólicas. [tese de doutorado]. Rio de Janeiro (RJ): Escola de Enfermagem Anna Nery/ UFRJ; 2006.

5-Oliveira EM, Melcop AG. Álcool e trânsito. Recife (PE): Instituto RAID; 1997.

6-Pinsky I, Laranjeira R. 0 fenômeno do dirigir alcoolizado no Brasil e no mundo: revisão de literatura. Rev ABP-APAL 1998; 20( 4): 16065.

7- Abreu AMM, Lima JMB, Alves TA. 0 impacto do álcool na mortalidade dos acidentes de trânsito: uma questão de saúde pública. Esc Anna Nery Rev Enferm 2006 abr; 10(1): 87-94.

8- Abreu AMM, Lima JMB, Silva LM. Níveis de alcoolemia e mortalidade por acidentes de trânsito na cidade do Ro de Janeiro. Esc Anna Nery Rev Enferm 2007 dez; 11(4): 575-80.

9- Velásquez HA, Eastman CA. Segurança no transito: um problema de política publica. Washington (USA): OPS ; 2004.

10- World Health Organization (WHO). World report or road traffic injury prevention. Summary. Genebra; 2004.

11- Alves, R.S. Toxicologia forense e saúde pública: desenvolvimento e avaliação de um sistema de informações como ferramenta para a vigilância e monitoramento de agravos decorrentes da utilização de substâncias químicas. [tese de doutorado]. Rio de Janeiro (RJ): Escola Nacional de Saúde Pública/FIOCRUZ; 2005.

12-Gazal-Carvalho C. Prevalência de alcoolemia em vítimas de causas externas admitidas em centro urbano de atenção ao trauma. Rev Saude Publica 2002; 36(1): 47-54.

13- levine B. Interpretation of low postmortem concentrations of ethanol. J Forensic Sci 1993 May; 38(3): 663-67.

14- National Highway Traffic Safety Administration ( NHTSA). National Center for Statistics \& Analysis(NCSA) [on-line].Washington- Early assessment of motor vechicle crashes. [updated 2003; cited 2005 Aug 30]. Available from: http://www.nhtsa.dot.gov/people/ncsa e http://www.nhtsa.dot.gov.

15- Savola 0. Blood alcohol is the best indicator of hazardous alcohol drinking in young adults and working: age patients with trauma. Alcohol \& Alcoholism 2004; 39(4): 340-45. 